\title{
Molecular identification of actinomycetes with antimicrobial, antioxidant and anticancer properties
}

\author{
Mohamed S Abdel-Aziz, Amal S Hathout, Aziza A El-Neleety, Ahmed A Hamed, \\ Bassem A Sabry, Soher E Aly, Mosaad Attia Abdel-Wahhab* \\ National Research Center, Cairo, Egypt \\ *Corresponding author, email: mosaad_abdelwahhab@yahoo.com
}

\begin{abstract}
The objectives of this study were to isolate and identify the actinomycetes strains from the soil and marine sediments and to evaluate the antimicrobial, antioxidant and cytotoxic activity of their bioactive secondary metabolites. Eight actinomycetes strains were isolated from soil and marine sediment samples collected from different areas in Egypt. Only three actinomycetes exhibited a wide spectrum of antimicrobial activities. They were active in vitro against microbial pathogen viz: Staphylococcus aureus, Escherichia coli, Salmonella typhi, Aspergillus parasiticus, Fusarium solani and Fusarium oxysporum. These promising isolates were selected and identified using molecular identification technique and identified as Streptomyces spp. The crude extracts from the three Streptomyces exhibited potent antimicrobial activities against a set of microbial pathogens as well as antioxidant and anticancer activity in human hepatocellular carcinoma cell line (HepG2). The crude extract of Streptomyces isolate D showed antitumor activity with $I_{50} 0.85 \mu \mathrm{g} / \mathrm{mL}$. Forty compounds were identified from the two most promising ethyl acetate extracts of culture broth of Streptomyces sp. (D-EGY) by Gas Chromatography-Mass Spectrometry analysis. It could be concluded that the streptomycetes isolated from the Egyptian environment are promising candidates as antimicrobial, antioxidant and anticancer.
\end{abstract}

Key words: Streptomyces; bacteria; fungi; cytotoxicity; GC-MS

\section{Introduction}

Moulds represent a great challenge confronting food and feed industry all over the world. The moulds cause great losses worldwide in food and feed supplementation due to the production of mycotoxins (Cheong et al., 2014). Contamination of foods by pathogenic bacteria (such as Salmonella typhimurium, Escherichia coli, Campylobacter jejuni, Legionella pneumophila, Staphylococcus aureus, etc.) results in numerous foodborne diseases (Targowski \& Płusa, 2015). Infectious diseases account for nearly $40 \%$ of the total 50 million annual estimated deaths worldwide, whereas in many developing countries microbial diseases constitute the major cause of death (Abdalhai et al., 2015).

In order to achieve improved food safety against such pathogens, several traditional means for the control of microbial spoilage and safety hazards in foods are being replaced by combinations of innovative technologies including the biological antimicrobial systems. Antimicrobial resistance among pathogenic microorganisms has led to a renewed search for new antimicrobial agents from microorganism such as actinomycetes.

Actinomycetes are Gram-positive, freeliving, spore forming, saprophytic, filamentous bacteria, extensively dispersed in water, soil which has an ecological significant in soil nutrient 
cycling for colonizing plants and have DNA with high GC content (69-73\%). Of all the genera of the actinomycetes, Streptomyces is the largest number of species and varieties occurred in nature and they are playing an extensive role in the pharmaceutical as well as medical industry for their capacity to produce secondary metabolites (Janardhan et al., 2014).

Over 10,000 bioactive secondary metabolites are produced by actinomycetes, representing $45 \%$ of all bioactive microbial metabolites discovered. Many of these bioactive compounds were isolated and characterized and have been developed into drugs for treatment of wide range of diseases in human, animals and the agriculture sectors (Subathra et al., 2013). Actinomycetes are the most prolific producers of antibiotics accounting for about $80 \%$ of the known antibiotics (Subramani \& Aalbersberg, 2012). Novel secondary metabolites with a wide range of biological activities may ultimately find applications as anti-infective, anticancer, antibacterial, antifungal, antiviral, anti-parasitic, immunosuppressive, enzyme inhibitory and diabetogenic (Kekuda et al., 2010). To cope up with the demand for these new pharmaceutical and agriculture compounds, researchers are looking for novel microorganisms in new environments. Therefore, the aim of the current research was to isolate and characterize new Egyptian soil and marine actinomycetes strains. The isolates were further screened for bioactive potential secondary metabolites to evaluate their ability as antimicrobial, antioxidant and cytotoxic activity.

\section{Material and methods}

Microorganisms

Gram+ve bacteria (Staphylococcus

aureus), Gram-ve bacteria (Escherichia coli, Pseudomonas aeruginosa, and Salmonella typhi), yeast (Candida albicans) as well as fungi (Aspergillus niger and Aspergillus parasiticus) were obtained from the culture collection of the Microbial Resources Centre (MIRCEN), Faculty of Agriculture, Ain Shams University, Cairo, Egypt. Fusarium solani, and Fusarium oxysporum were isolated from maize samples in Egypt.

Sample collection
Soil samples were collected from agricultural soil surrounding Mansoura city, Dakahlia governorate (coordinates are latitude $31^{\circ} \mathrm{N}$ and longitude $31^{\circ} \mathrm{E}$ ), Egypt during April, 2015. The samples were taken at $10 \mathrm{~cm}$ depth using sterile spatula and each sample was placed in sterile plastic bags and transferred to the microbiology laboratory at Microbial Chemistry Department, National Research Centre, Dokki, Cairo, Egypt. The samples were sieved and air dried for $3-5$ days at $25^{\circ} \mathrm{C}$ then was kept at $10^{\circ} \mathrm{C}$ in an incubator until used for the isolation of actinomycetes. Marine sediments samples were collected from Ras Sedr city, Suez Gulf, South Sinai governorate (coordinates are latitude $29^{\circ} \mathrm{N}$ and longitude $32^{\circ} \mathrm{E}$ ), Egypt during May, 2015 under aseptic conditions using a piston core sediment sampler at a depth of $4-5 \mathrm{~cm}$ and stored at $4^{\circ} \mathrm{C}$ in Microbial Chemistry Laboratory, National Research Centre.

\section{Isolation of actinomycetes}

Dried soil samples (50g) were suspended separately in $200 \mathrm{~mL}$ of sterile distilled water and shaken on a reciprocal shaker for $2 \mathrm{~h}$. The isolation of actinomycetes was carried out using starch-nitrate agar (SNA) consisting of 20 $\mathrm{g} / \mathrm{L}$ starch, $1 \mathrm{~g} / \mathrm{L} \mathrm{KNO}_{3}, 0.5 \mathrm{~g} / \mathrm{L} \mathrm{K}_{2} \mathrm{HPO}_{4}, 0.5 \mathrm{~g} / \mathrm{L}$ $\mathrm{MgSO}_{4} .7 \mathrm{H}_{2} \mathrm{O}, 0.5 \mathrm{~g} / \mathrm{L} \mathrm{NaCl}, 0.01 \mathrm{~g} / \mathrm{L} \mathrm{FeSO}_{4^{\prime}} 15$ $\mathrm{g} / \mathrm{L}$ agar and supplemented with nystatin at a concentration of $50 \mu \mathrm{g} / \mathrm{mL}$ as an antifungal and nalidixic acid at a concentration of $20 \mu \mathrm{g} / \mathrm{mL}$ as an antibacterial (Sineva \& Terekhova, 2015). However, marine sediments (1 g) were suspended in $100 \mathrm{~mL}$ of $0.8 \%$ sterile saline solution and agitated for 30 min using orbital shaker incubator (100 rpm) at $30^{\circ} \mathrm{C}$. The isolation of actinomycetes from marine sediments was carried out using starch-casein agar (SCA) consisting of $10 \mathrm{~g} / \mathrm{L}$ soluble starch, $2 \mathrm{~g} / \mathrm{L} \mathrm{K}_{2} \mathrm{HPO}_{4}, 2 \mathrm{~g} / \mathrm{L} \mathrm{KNO}_{3}, 0.3 \mathrm{~g} / \mathrm{L}$ casein, $0.05 \mathrm{~g} / \mathrm{L} \mathrm{MgSO}+7 \mathrm{H}_{2} \mathrm{O}, 0.02 \mathrm{~g} / \mathrm{L} \mathrm{CaCO}_{3}$, $0.01 \mathrm{~g} / \mathrm{L} \mathrm{FeSO}_{4} \cdot 7 \mathrm{H}_{2} \mathrm{O}, 15 \mathrm{~g} / \mathrm{L}$ agar and $1000 \mathrm{~mL}$ filtered sea water supplemented with $25 \mu \mathrm{g} / \mathrm{mL}$ cyclohexamide and $10 \mu \mathrm{g} / \mathrm{mL}$ nalidixic acid to minimize contamination with fungi and bacteria, respectively. The shaken suspensions for soil or marine samples were diluted using serial dilution procedure $\left(10^{-1}\right.$ to $\left.10^{-6}\right)$ and aliquots $(100 \mu \mathrm{L})$ from the different dilutions were used to inoculate the 
medium plates. The plates were incubated at $30^{\circ} \mathrm{C}$ for two weeks. The growing colonies were sub-cultured and transferred to slants without the antibiotic substance and kept at $4^{\circ} \mathrm{C}$ until use. These actinomycetes strains were maintained on SNA and SCA medium and incubated for 14 days in an incubator in the dark at $28^{\circ} \mathrm{C}$. The micromorphology and sporulation were observed by optics microscopy (Olympus, Japan).

\section{Antagonistic activity of actinomycetes isolates}

The plate diffusion method was used for the antagonistic assay of the actinomycetes isolates. In brief, the isolates were removed from their agar using a sterile cork bore $15 \mathrm{~mm}$ in diameter) and placed onto agar plate lawn with the pathogenic fungi or bacteria e.g. A. parasiticus, F. Solani, F. oysporum, E. coli, S. typhi and $S$. aureus and incubated at $37^{\circ} \mathrm{C}$ for $24 \mathrm{~h}$ for bacteria and $28^{\circ} \mathrm{C}$ for 5 days for fungi. The formation of halo zone was considered as positive reaction. The diameter of the growth inhibition zones were measured averaged and the mean values were recorded.

Molecular identification of actinomycetes isolates

The three actinomycetes isolates (showed the highest antagonistic activity against the tested pathogenic fungi and bacteria) were identified according to a molecular biological protocol by DNA isolation, amplification (PCR) and sequencing of the ITS region. The forward primers 27F (5'-AGAGTTTGATCMTGGCTCAG-3'), and 518F (5'-CCAGCAGCCGCGGTAATACG-3') and reverse 1492R (5'-TACGGYTACCTTGTTACGACTT-3'), and 800R (5'-TACCAGGGTATCTAATCC-3') were used. The purification of the PCR products was carried out to remove unincorporated $P C R$ primers and dNTPS from PCR products by using Montage PCR Clean up kit (Millipore). Sequencing was performed using Big Dye terminator cycle sequencing kit (Applied BioSystems, USA). Sequencing products were resolved on an Applied Biosystems model 3730XL automated DNA sequencing system (Applied BioSystems, USA). Amplification and sequencing of the 16S rRNA gene had been done according to Myer et al. (2016). Blast program was used to assess the DNA similarities (www.ncbi.nlm.nih.gov/blst).

\section{Preparation of Streptomyces species extracts}

The identified Streptomyces species were cultivated on starch nitrate agar plate medium at $28^{\circ} \mathrm{C}$ for $7-14$ days (until complete sporulation). One-litre Erlenmeyer flasks, each containing 250 $\mathrm{mL}$ of ISP2 medium consisting of $4 \mathrm{~g} / \mathrm{L}$ glucose, 4 $\mathrm{g} / \mathrm{L}$ yeast extract, and $10 \mathrm{~g} / \mathrm{L}$ malt extract, were inoculated with spore suspension from well grown slants (only one slant was used to inoculate two flasks). The flasks were incubated at $30^{\circ} \mathrm{C}$ using rotary shaker (150 rpm) or static in self incubator at the same temperature for 15 days. The cells were separated by centrifugation at $5000 \mathrm{rpm}$ and $4^{\circ} \mathrm{C}$, and both the cell-free supernatant and the cells biomasses were subject to extraction. The supernatants were extracted with ethyl acetate 3 times. However, the cell biomasses were extracted with acetone then the acetone evaporated under vacuum and the remaining water residue was re-extracted 3 times with acetyl acetate (Shaaban et al., 2013). The yielded extracts form the cell-free supernatant or the cells biomasses of the three Streptomyces species using different routes are presented in Table 1.

\section{Antimicrobial activity}

The antimicrobial activities of crude extracts of the isolated Streptomyces spp. were tested against S. aureus, C. albicans, F. oxysporum, $P$. aeruginasa and $A$. niger. The obtained extracts were dissolved in methanol and filter paper discs $(5 \mathrm{~mm}$ diameter, Whatman No.1) were saturated with $10 \mu \mathrm{L}$ from the water or the methanol extract, and dried for $1 \mathrm{~h}$ at room temperature under sterilized conditions (final extract concentration was $100 \mathrm{\mu g}$ per disc). The paper discs were placed on inoculated agar plates with the tested microbes and incubated at the appropriate temperature and time for each microorganism. Bacterial strains were grown on nutrient agar; yeast strains were grown Potato dextrose agar (PDA) medium (DSMZ GmbH, Germany), and the fungal strain was grown on Czapek-Dox medium (DSMZ GmbH, Germany). After the incubation period, the diameter of the 
growth inhibition zones were measured averaged and the mean values were recorded. Neomycin and cycloheximide at a concentration of $50 \mu \mathrm{g} /$ disc were used as antibacterial and antifungal control agents, respectively.

Table 1.Crude extracts of Streptomyces sp. and extraction conditions

\begin{tabular}{lcl}
\hline Streptomyces sp. & Extract number & Extraction conditions \\
\hline $5 S 2-E G Y$ & I & Extracted from supernatant incubated under rotary shaking \\
& II & Extracted from cells incubated under rotary shaking \\
III & Extracted from supernatant incubated under static \\
V & Extracted from cells incubated under static \\
VI & Extracted from supernatant incubated under rotary shaking \\
D- EGY & VII & Extracted from cells incubated under rotary shaking \\
& VIII & Extracted from cells incubated under static \\
IX & Extracted from supernatant incubated under rotary shaking \\
X & Extracted from cells incubated under rotary shaking \\
XI $1-E G Y$ & Extracted from supernatant incubated under static \\
& XII & Extracted from cells incubated under static \\
\hline
\end{tabular}

Antioxidant activity (DPPH scavenging assay)

The crude extracts of the bioactive secondarymetabolitesshowing high antimicrobial activity were studied for their antioxidant activity. One hundred $\mu \mathrm{L}$ of the extracts at concentrations of $5,7.5$ and $10 \mathrm{mg} / \mathrm{mL}$ were added to $5 \mathrm{~mL}$ of the 2,2-Diphenyl-1-Picrylhydrazyl (DPPH) solution (0.005\% in methanol). After $30 \mathrm{~min}$ incubation at room temperature, the absorbance was read against pure methanol at $520 \mathrm{~nm}$. The radical-scavenging activities of the samples were calculated as percentages of inhibition according to the following equation:

$$
\text { DPPH } \%=\frac{A \text { blank }- \text { A sample }}{A \text { blank }} \times 100
$$

Where: A blank is the absorbance of the control (containing all reagents except the test compound), and A sample is the absorbance of the test compound. All tests were done in triplicate.

\section{Cytotoxic activity}

Hepatocellular Carcinoma Cell Line (HepG2)

Potential cytotoxicity of actinomycetes secondary metabolites crude extracts was performed. Briefly, human hepatocellular carcinoma cell line (HepG2) (1×104 cells/well), obtained from the National Cancer Institute, Cairo University, Cairo, Egypt, were seeded in 96-microwell plate and allowed to grow overnight before the treatment with the crude extracts of actinomycetes to allow attachment of the cell to the wall of the plate. Different concentrations of the crude extracts 10.39 - 50 $\mu \mathrm{g} / \mathrm{mL}$ ) were added to the cells monolayer and triplicate wells were prepared for each individual extract. Monolayer cells were incubated with the extract in humidified incubator with $5 \% \mathrm{CO}_{2}$ at $37^{\circ} \mathrm{C}$ and after $48 \mathrm{~h}$; cells were fixed by the addition of $25 \mu \mathrm{L}$ of cold $50 \%$ trichloroacetic acid (TCA). After incubation for one hour at $4^{\circ} \mathrm{C}$, the plate was washed five times with tap water to remove TCA, medium and dead cells then the plate was dried in air. Fifty $\mu \mathrm{L}$ of $0.4 \%$ sulforhodamine B stain dissolved in $1 \%$ acetic acid was added to each well and allowed to stand for $30 \mathrm{~min}$. The plate was subsequently washed four times with $1 \%$ acetic acid to remove excess stain then dried in air again. One hundred and $50 \mu \mathrm{L}$ of $10 \mathrm{mM}$ aqueous Tris-Base [tris(hydroxylmethyl) aminomethane] was added to solubilize the cellbound dye. The plate was then shaken for $10 \mathrm{~min}$ followed by the reading of optical density (OD) at $570 \mathrm{~nm}$ in a microplate spectrophotometer.

Identification of chemical composition of the crude extracts of using GC-MS

The most promising two crude extracts ( $V$ and VII) that showed high antimicrobial and cytotoxic activities were analysed by a coupled Varian gas chromatography/ mass spectrometry (Perkin Elmer Auto XL GC, Waltham, MA, USA) equipped with a flame ionization detector to identify their chemical composition. The GC 
conditions were EQUITY-5 column $(60 \mathrm{~m} \times 0.32 \mathrm{~mm}$ $\times 0.25 \mu \mathrm{m}) ; \mathrm{H}_{2}$ carrier gas; column head pressure 10 psi, the oven temperature was maintained initially at $70^{\circ} \mathrm{C}$ for $2 \mathrm{~min}$, and then programmed from 70 to $250^{\circ} \mathrm{C}$ at a rate of $3^{\circ} \mathrm{C} / \mathrm{min}$. The ionization voltage was $70 \mathrm{eV}$, mass range m/z 39-400 amu. The identification of individual compounds was based on their retention times relative to those of authentic samples and matching spectral peaks available with the published data.

\section{Statistical analysis}

All data were statistically analyzed by analysis of Variance (ANOVA). The significance of the differences among treatment groups was determined by Waller-Duncan k-ratio (Waller \& Duncan, 1969). All statements of significance were based on probability of $\mathrm{P} \leq 0.05$.

\section{Results}

Isolation of actinomycetes

Four actinomycetes species were isolated from soil samples and nomeados S14,

Table 2. Antimicrobial activity of actinomycetes species
AM2, S3 and L. Other 4 species were isolated from marine sediments samples and nomeados 5S1, 5S2, D and 25. It is of interest to mention that the genus Streptomyces was the dominant in all species in the marine sediments samples.

Antagonistic activity of the isolated actinomycetes

The results of antagonistic activity of the isolated actinomycetes presented in Table 2 revealed that only three isolates e.g. 5S1, 5 S2 and $D$ showed the highest antagonistic activity against most of the tested microorganisms. Two isolates e.g. AM2 and L showed only antagonistic activity against the tested fungi but not against bacteria and only one isolate (S3) did not show any antifungal or antibacterial activity (Table 2). Consequently, the three actinomycetes isolates that showed strong antimicrobial activity (5S1, 5S2 and D) were subjected to molecular identification technique.

Molecular Identification of the actinomycetes isolates 5S1, $5 S 2$ and D

\begin{tabular}{lcccccc}
\hline \multirow{2}{*}{$\begin{array}{c}\text { Actinomycetes } \\
\text { Isolates }\end{array}$} & \multicolumn{5}{c}{ Inhibition zone $(\mathrm{mm})$} \\
\cline { 2 - 7 } 5S1 & A. parasiticus & F. solani & F. oysporum & E. coli & S. typhi & S. aureus \\
\cline { 2 - 7 } 5S2 & $25.0 \pm 0.0$ & $30.0 \pm 0.0$ & $20.5 \pm 0.05$ & $10.5 \pm 0.05$ & ND & $10.5 \pm 0.05$ \\
D & $27.0 \pm 5.0$ & $26.5 \pm 1.5$ & $19.0 \pm 0.0$ & $10.0 \pm 0.05$ & ND & $10.0 \pm 0.05$ \\
S14 & $25.0 \pm 5.0$ & $30.0 \pm 0.0$ & $23.0 \pm 2.0$ & $12.0 \pm 1.0$ & $14 \pm 0.0$ & $12.0 \pm 1.0$ \\
AM2 & $10.0 \pm 10$ & $22.5 \pm 2.5$ & $20.0 \pm 0.0$ & ND & ND & ND \\
L & $15.0 \pm 0.0$ & $30.0 \pm 5.0$ & ND & ND & ND & ND \\
S3 & ND & $13.5 \pm 0.05$ & $14.0 \pm 1.0$ & ND & ND & ND \\
25 & ND & ND & ND & ND & ND & ND \\
\hline Results are mean \pm SEM. ND: Non detected & ND & ND & ND & ND & ND \\
\hline
\end{tabular}

The molecular identification of the three actinomycetes revealed that a nucleotide sequence of 967,971 and $1054 \mathrm{bp}$ of the whole 165 rRNA gene of the Streptomyces sp. for isolate $5 S 1,5 S 2$ and D, respectively was determined in both strands. BLAST search revealed that $\mathbf{9 9 \%}$ similarity to Streptomyces sp. and the phylogenetic trees of these streptomyces were also constructed (Figure la-c). The gene sequences of actinomycetes were deposited in GenBank database; as Streptomyces sp. 5S1EGY (Accession No. KP336669.1), Streptomyces sp. 5S2-EGY (Accession No. KP336670.1), and Streptomyces sp. D-EGY (Accession No. KP336671.1). It is well known that the traditional identification techniques are depending on the culture morphology and some biochemical reactions are known to be a time consuming methods that also need a talented persons with very high experience (Sugita \& Nishikawa, 2003). Consequently, the use of DNA sequences in the current study was proved to be an objective, reproducible, accurate and quick tools for identification. Universal primers: 27F (5'GAGTTTGATCATGGCTCAG3'), 1492R (5'GGTTACCTTGTTACGACTT3') [for PCR] and 518F (5'CCAGCAGCCGCGGTAATACG3') and 800R (5'TACCAGGGTATCTAATCC3') were used in the study of the genotypic identification of microorganisms isolated from non-parenteral 
Abdel-Aziz et al. (2019) / Molecular identification of ...



Figure 1. Phylogenetic tree showing relationship of strain $5 S 1$ (a), $5 S 2$ (b) and $D(\mathbf{c})$, and the type strains of closely related Streptomyces species constructed using the neighbour-joining method and based on 165 rRNA gene sequences. 
pharmaceutical formulations. Moreover, the primers $27 \mathrm{~F}$ and $1492 \mathrm{R}$ were used for the identification of bacteria.

Antimicrobial activity of crude extract of Streptomyces sp

The crude extracts of the three isolates
$5 S 1,5 S 2$ and D were used to investigate the antimicrobial activity against pathogenic microorganisms. The results revealed that the extracts of these isolates inhibited the growth of pathogenic microorganisms at varying degrees (Figure 2).

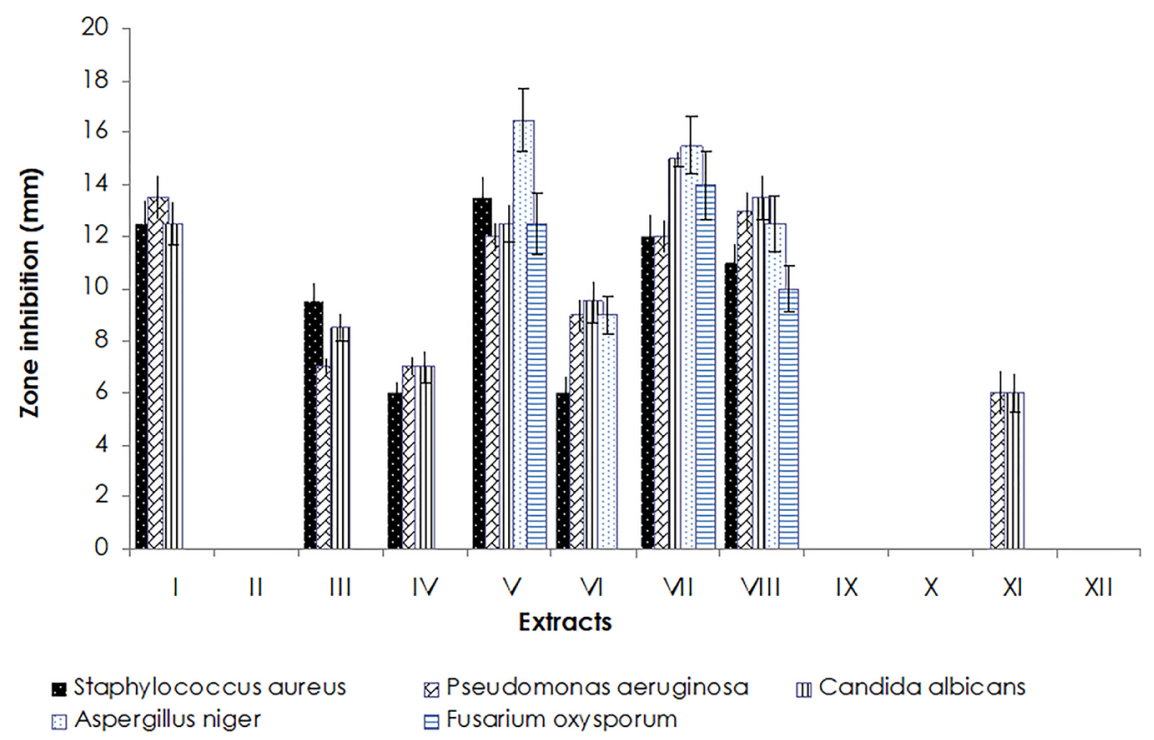

Figure 2. Antimicrobial activity of actinomycetes crude extracts. Results are mean \pm SEM. Methanol and water, used as controls showed no zone inhibition

The extract isolated from the two actinomycetes strains ( $D$, and $5 S 2$ ) inhibited the growth of nearly all the tested microorganisms, whereas the third actinomycetes extract (5S1) did not show any inhibition of the tested organisms. These extracts showed antimicrobial activities against the two tested bacteria and Candida albicans. Neomycin as anti bacterial standard exhibited the following results: S. aureus (18 mm), P. aeruginosa $(21 \mathrm{~mm})$, C. albicans $(23 \mathrm{~mm})$ and $A$. niger $(0 \mathrm{~mm})$. On the other hand Cyclohexamide as antifungal standard exhibited the following results: $S$. aureus $(0 \mathrm{~mm}), P$. aeruginosa $(0 \mathrm{~mm}), C$. albicans $(0 \mathrm{~mm})$ and $A$. niger $(26 \mathrm{~mm})$. Negative controls (discs with water and methanol) did not exhibit any antimicrobial activity against any the tested microorganisms.

\section{Antioxidant activity}

The crude extracts showing high antimicrobial activity (i.e. extracts I, III, V, VI, VII, and VIII) were evaluated for their antioxidant activity. The results DPPH free radical scavenging activity (\%) of different ethyl acetate extracts of both Streptomyces species are shown in Figure
3. The degree of stable DPPH* decolourization to $\mathrm{DPPHH}$ yellow (reduced form of DPPH) indicated the scavenging efficiency of the extract. The recorded values of radical scavenging ability of different extracts I, III, V, VI, VII, and VIII at a concentration of $10 \mathrm{mg} / \mathrm{mL}$ were $82.06,46.71$, $20.52,14.74,18.74$, and $11.01 \%$ respectively.

Cytotoxic activity

Human hepatocellular carcinoma cell lines (HepG2) was used as a model system to examine the cytotoxic effect of the isolated Streptomyces crude extracts at a concentration varied from 0.39 to $50 \mu \mathrm{g}$. The concentration of the crude extracts leading to $50 \%$ of cytotoxicity was then determined. The results presented in Figure 4 showed that the ethyl acetate extract of the isolate $D$ caused an inhibitory activity against HepG2 cell lines with $I_{50}=0.85 \mu \mathrm{g}$. The results presented in Figure 5 and the regression analysis presented in Figure 6 also showed the effects of these extracts on HepG2 cell line viability.

Identification of chemical composition by GC-MS Based on the above mention results, the crude extract of static and of shaken culture supernatant of Streptomyces isolate D showed 


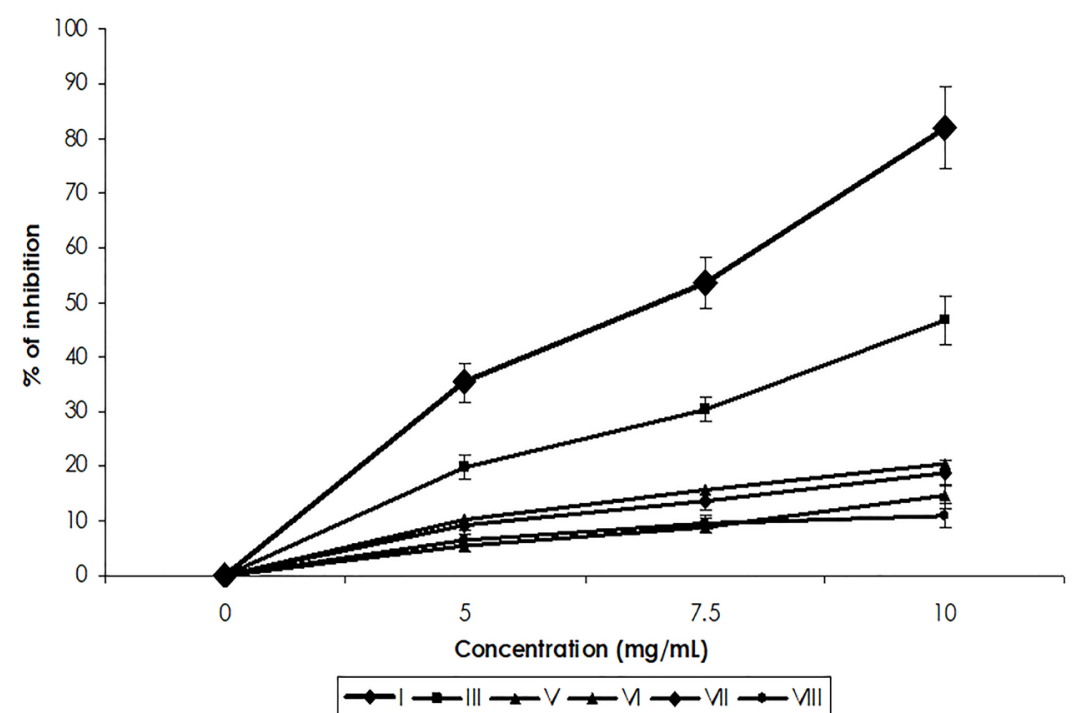

Figure 3. Antioxidant activity of actinomycetes crude extracts measured by DPPH assay. Results are mean \pm SEM

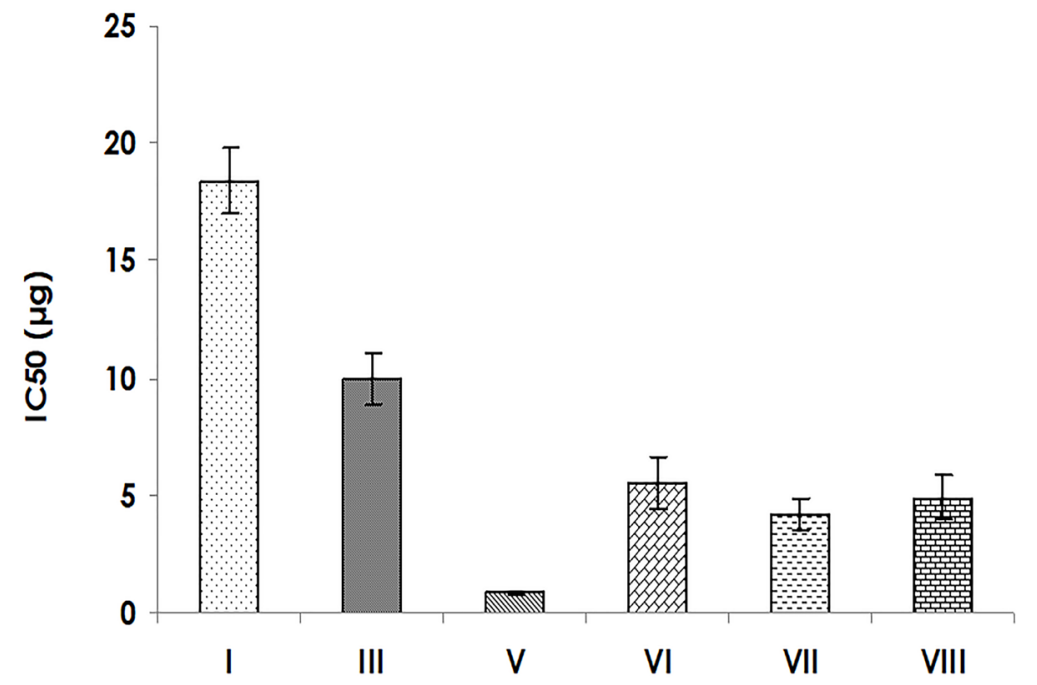

Figure 4. Evaluation of cytotoxicity $\left(I_{C_{50}}\right)$ against hepatocellular carcinoma. Results are mean \pm SEM
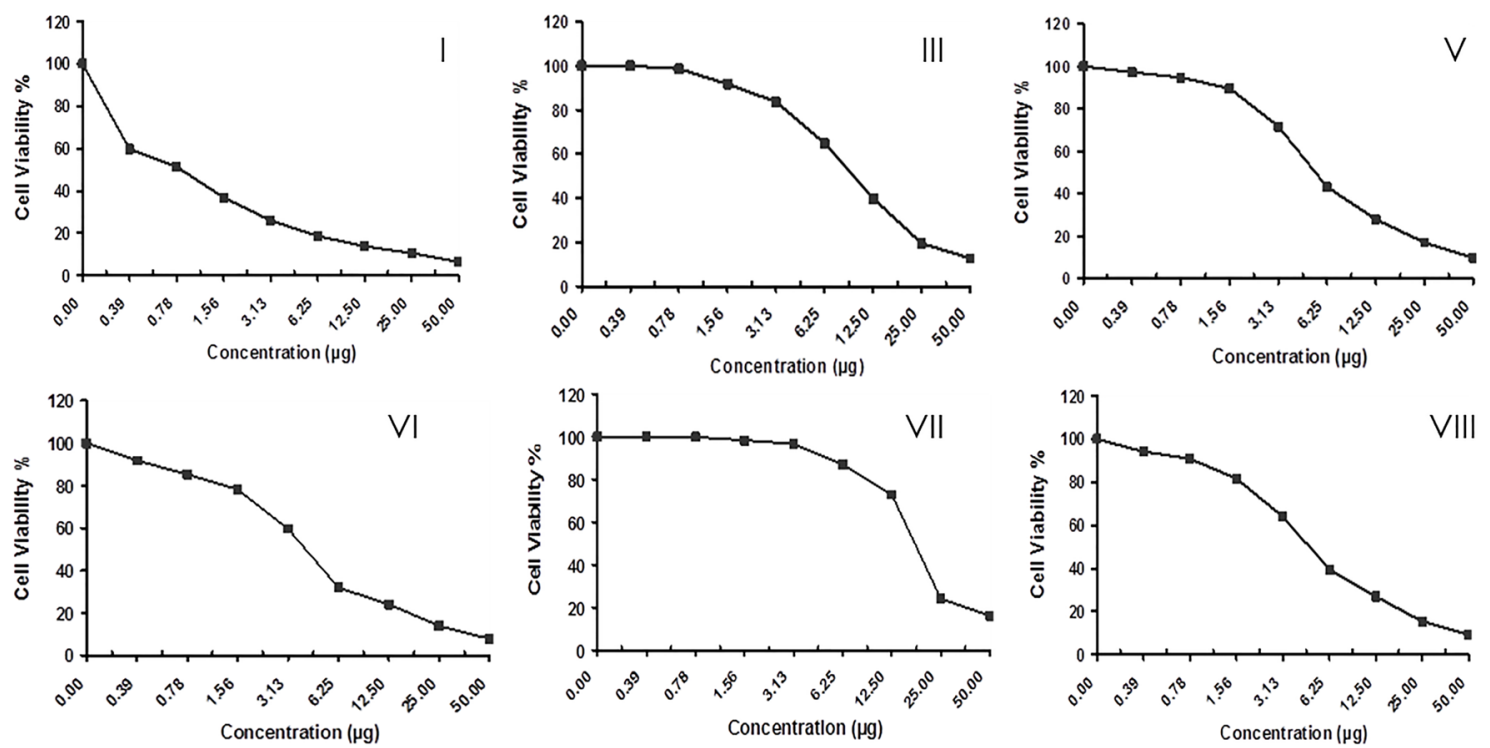

Figure 5. Effects of secondary metabolites extracted from Streptomyces sp. on HepG2 cell line viability 

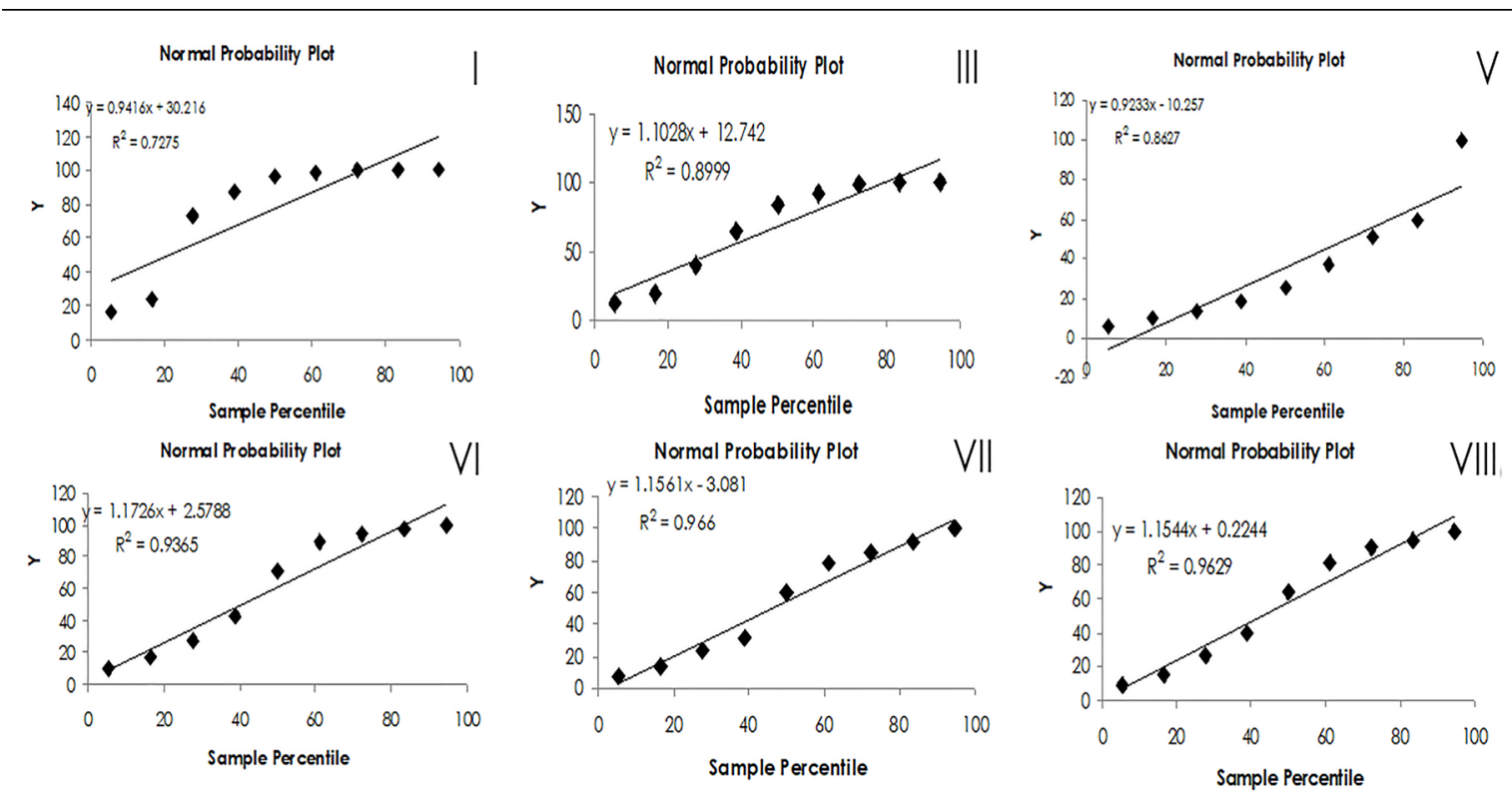

Figure 6. The regression analysis for the effect of secondary metabolites extracted from Streptomyces sp. on HepG2 cell line viability

the highest antimicrobial, antioxidant and cytotoxic effects. Consequently, these extracts were subjected to the identification of their active components. The chemical analysis of these crude extracts indicated the identification of 40 components for each extract, representing 98.84\% and $99.98 \%$ respectively (Tables 4 and 5). The major components in the extract of rotary shaker of the culture supernatant of $D$ isolate (extract V) were, Butane, 2, 3-bis (trimethylsiloxy) (14.89\%), 3-Trifluoromethylsulfonyl-4,5-dihydro$2 \mathrm{H}$-furan (11.37\%), Allyl mercaptan (11.21\%), 2,3-Butanediol, O-(trimethylsilyl)-, monoacetate (10.66\%), Butanoic acid, trimethylsilyl ester (9.83\%), Bis(2-ethylhexyl) phthalate (8.59\%) and Ethanedioic acid, bis (trimethylsilyl) ester ( $8.22 \%$ ) with the retention time $7.80,6.41,5.45,11.15$, 10.60, and 62.97, respectively (Table 4). On the other hand, the major components in extract of the static culture supernatant of the same isolate (extract VII) were 1, 2-Dimethyl-2-pyrrolino [3, 2-c] pyridine (19.08\%), 3-(4Vinyl benzyloxy) benzyl alcohol (18.37\%), 3-Octanol-3, 6-dimethyl (12.66\%) and 1, 2-Benzene dicarboxylic acid, diisooctyl ester (7.38\%) with the retention time 7.86, 7.80, 26.48 and 62.94, respectively (Table 5).

\section{Discussion}

Streptomyces are the largest antibioticproducing genus has antifungal, antibacterial, antiparasitic drugs and also a wide range of other bioactive compounds such as immunosuppressants. However, isolation of actinomycetes has always been faced with the difficulties in comparison to their competitors such as other bacteria and fungi which may be due to their long incubation period. The actinomycetes isolation ratio was increased by pre-treatment of the samples by subjecting them to dry air for three weeks.

In the current study, the isolated actinomycetes showed high antagonistic activity against several pathogenic fungi and bacteria. Patel et al. (2014) reported that $79 \%$ of the actinomycetes isolates were active against at least one of the 18 tested pathogens. Other reports indicated that actinomycetes isolates showed inhibitory activity against mycelial growth of plant pathogenic fungi like Alternaria mali, Colletotrichum gloeosporides, F. oxysporum (Lim et al., 2000); against yeasts and gram positive and gram negative antibiotic resistant pathogens (Thirumalairaj et al., 2015).

The three actinomycetes isolates that showed the highest antagonistic effect against the tested microorganisms (i.e 5S1, 5S2 and D) were identified as Streptomyces spp. by using $16 \mathrm{~S}$ rRNA molecular technique.

The crude extract of the bioactive compounds isolated from the three isolates of Streptomyces showed antimicrobial activity against different microorganisms. Similar results were reported by Khamna et al. (2009) who found that the crude extract was active as antifungal 
Table 4. Chemical compositions of the ethyl acetate extract (V) of the filtrate of shaken culture broth of Streptomyces sp. D-EGY.

\begin{tabular}{|c|c|c|c|c|c|}
\hline No. & RT & Area \% & M.W & M.F. & Compound name \\
\hline 1 & 5.02 & 0.73 & 132 & $\mathrm{C}_{6} \mathrm{H}_{16} \mathrm{OSi}$ & Silane, trimethylpropoxy \\
\hline 2 & 5.33 & 3.97 & 990 & $\mathrm{C}_{60} \mathrm{H}_{78} \mathrm{~S}_{6}$ & $\begin{array}{c}\text { 1,4-Bis(3,3",4,4"-tetra butyl-2,2':5',2"-terthie n-2-yl)-1,3- } \\
\text { butadiyne }\end{array}$ \\
\hline 3 & 5.45 & 11.21 & 74 & $\mathrm{C}_{3} \mathrm{H}_{6} \mathrm{~S}$ & Allyl mercaptan \\
\hline 4 & 6.15 & 0.85 & 162 & $\mathrm{C}_{6} \mathrm{H}_{18} \mathrm{OSi}_{2}$ & Dimethyl(trimethylsilyl) methoxy silane \\
\hline 5 & 6.41 & 11.37 & 202 & $\mathrm{C}_{5} \mathrm{H}_{5} \mathrm{~F}_{3} \mathrm{O}_{3} \mathrm{~S}$ & 3-Trifluoromethylsulfonyl-4,5-dihydro-2H-furan \\
\hline 6 & 6.71 & 8.22 & 234 & $\mathrm{C}_{8} \mathrm{H}_{18} \mathrm{O}_{4} \mathrm{Si}_{2}$ & Ethanedioic acid, bis(trimethylsilyl) ester \\
\hline 7 & 7.04 & 0.12 & 148 & $\mathrm{C}_{7} \mathrm{H}_{8} \mathrm{~N}_{4}$ & s-Triazolo[4,3-a]pyrazine, 3-ethyl \\
\hline 8 & 7.13 & 0.28 & 130 & $\mathrm{C}_{7} \mathrm{H}_{14} \mathrm{O}_{2}$ & (S)-6-Hydroxyheptanoic acid 1,2 \\
\hline 9 & 7.19 & 0.24 & 131 & $\mathrm{C}_{6} \mathrm{H}_{10} \mathrm{CIN}$ & 5-Chloro-1,4-dimethyl-2,3-dihydro-1H-pyrrole \\
\hline 10 & 7.41 & 0.52 & 320 & $\mathrm{C}_{20} \mathrm{H}_{20} \mathrm{~N}_{2} \mathrm{O}_{2}$ & Bis[2-(1-methylethenyl)anilide] \\
\hline 11 & 7.51 & 0.99 & 172 & $\mathrm{C}_{11} \mathrm{H}_{12} \mathrm{~N}_{2}$ & 4-(1-Aminobut-3-enyl) benzonitrile \\
\hline 12 & 7.57 & 0.68 & 323 & $\mathrm{C}_{19} \mathrm{H}_{33} \mathrm{NO}_{3}$ & Phenol, 2,6-di(tert-butyl)-4-bis (2-hydroxyethyl)amin \\
\hline 13 & 7.80 & 14.89 & 234 & $\mathrm{C}_{10} \mathrm{H}_{26} \mathrm{O}_{2} \mathrm{Si}_{2}$ & Butane, 2,3-bis(trimethylsiloxy ) \\
\hline 14 & 8.13 & 0.35 & 413 & $\mathrm{C}_{19} \mathrm{H}_{39} \mathrm{NO}_{3} \mathrm{Si}_{3}$ & $\begin{array}{c}\text { Silanamine, N-[2-[3-methoxy-4-[(trimethylsilyl)oxy]phenyl]- } \\
\text { N, 1,1,1-tetramethyl-2-[(trimethylsilyl)oxy]ethyl]- }\end{array}$ \\
\hline 15 & 8.40 & 3.13 & 2084 & NA & Sscfggridrigaq Sglggns/3 \\
\hline 16 & 9.84 & 1.20 & 2027 & NA & Cnckapetascarr Cqqh/2 \\
\hline 17 & 10.60 & 9.83 & 160 & $\mathrm{C}_{7} \mathrm{H}_{16} \mathrm{O}_{2} \mathrm{Si}_{7}$ & Butanoic acid, trimethylsilyl ester \\
\hline 18 & 11.15 & 10.66 & 204 & $\mathrm{C}_{9} \mathrm{H}_{20} \mathrm{O}_{3} \mathrm{Si}$ & 2,3-Butanediol, O-(trimethylsilyl)-, monoacetate ${ }^{1}$ \\
\hline 19 & 13.85 & 0.61 & 471 & $\mathrm{C}_{21} \mathrm{H}_{45} \mathrm{NO}_{3} \mathrm{Si}_{4}$ & Epinephrine-Tetratms \\
\hline 20 & 13.97 & 0.30 & 415 & $\mathrm{C}_{27} \mathrm{H}_{45} \mathrm{NO}_{2}$ & 6á-Nitrocholest-4-ene \\
\hline 21 & 14.09 & 0.83 & 266 & $\mathrm{C}_{15} \mathrm{H}_{26} \mathrm{O}_{2} \mathrm{Si}$ & 1-Methoxy5-trimethylsilyloxy-3-phenylpentane \\
\hline 22 & 14.22 & 0.21 & 280 & $\mathrm{C}_{16} \mathrm{H}_{28} \mathrm{O}_{2} \mathrm{Si}$ & 1-Methoxy-5-dimethyl (ethyl)silyloxy-3-phenylpentane \\
\hline 23 & 14.30 & 0.23 & 200 & $\mathrm{C}_{11} \mathrm{H}_{24} \mathrm{OSi}$ & Butyl(dimethyl)silyloxy cyclopentane \\
\hline 24 & 14.63 & 0.60 & 202 & $\mathrm{C} 9 \mathrm{H} 18 \mathrm{O} 3 \mathrm{Si}$ & Pantoyl lactone, trimethyl silyl \\
\hline 25 & 16.54 & 0.18 & 326 & $\mathrm{C}_{15} \mathrm{H}_{28} \mathrm{~B}_{2} \mathrm{O}_{6}$ & $\begin{array}{l}\text { à-D-Mannopyranoside, methyl, cyclic } \\
\text { 2,3:4,6-bis(butylboronate) }\end{array}$ \\
\hline 26 & 19.77 & 0.41 & 306 & $\mathrm{C}_{13} \mathrm{H}_{30} \mathrm{O}_{4} \mathrm{Si}_{2}$ & 2-Mono-isobutyrin, bis(trimethylsilyl) \\
\hline 27 & 22.36 & 0.27 & 314 & $\mathrm{C}_{17} \mathrm{H}_{38} \mathrm{OSi}_{2}$ & 11-(Trimethylsilylmethyl) dimethylsilyloxy-1 -undecene \\
\hline 28 & 23.86 & 0.44 & 358 & $\mathrm{C}_{21} \mathrm{H}_{18} \mathrm{~N}_{4} \mathrm{O}_{2}$ & $\begin{array}{l}\text { 1-Amino-2-cyano-3,4-d ihydro-4-ethoxycarbo nyl-3- } \\
\text { phenylpyrido[1, 2-a] benzimidazole' }\end{array}$ \\
\hline 29 & 26.29 & 0.82 & 274 & $\mathrm{C}_{11} \mathrm{H}_{23} \mathrm{BO}_{5} \mathrm{Si}$ & $\begin{array}{l}\text { à-L-Galactopyranoside, methyl 6-deoxy-2-O- } \\
\text { (trimethylsilyl)-, cyclic methylboronate }\end{array}$ \\
\hline 30 & 40.53 & 0.21 & 256 & $\mathrm{C}_{16} \mathrm{H}_{32} \mathrm{O}_{2}$ & Tetradecanoic acid, 12-methyl-, methyl ester \\
\hline 31 & 43.27 & 0.80 & 284 & $\mathrm{C}_{18} \mathrm{H}_{36} \mathrm{O}_{2}$ & i-Propyl 12-methyltetradecanoate \\
\hline 32 & 44.94 & 0.51 & 270 & $\mathrm{C}_{17} \mathrm{H}_{34} \mathrm{O}_{2}$ & Pentadecanoic acid, 14-methyl-, methyl ester \\
\hline 33 & 46.96 & 0.47 & 210 & $\mathrm{C}_{11} \mathrm{H}_{18} \mathrm{~N}_{2} \mathrm{O}_{2}$ & 1,4-diaza-2,5-dioxo-3isobutyl bicyclo[4.3.0] nonane \\
\hline 34 & 47.45 & 0.43 & 330 & $\mathrm{C}_{19} \mathrm{H}_{38} \mathrm{O}_{4}$ & Hexadecanoic acid, 2,3-dihydroxypropyl ester \\
\hline 35 & 47.97 & 2.47 & 234 & $\mathrm{C}_{17} \mathrm{H}_{30}$ & 3-Methylene-9-pentyl piro[5.5] undecane \\
\hline 36 & 50.24 & 0.83 & 294 & $\mathrm{C}_{19} \mathrm{H}_{34} \mathrm{O}_{2}$ & 9,12-Octadecadienoic acid, methyl ester, (E,E) \\
\hline 37 & 50.39 & 0.18 & 296 & $\mathrm{C}_{19} \mathrm{H}_{36} \mathrm{O}_{2}$ & 16-Octadecenoic acid, methyl ester \\
\hline 38 & 52.19 & 0.62 & 308 & $\mathrm{C}_{20} \mathrm{H}_{36} \mathrm{O}_{2}$ & Linoleic acid ethyl ester \\
\hline 39 & 52.35 & 0.72 & 308 & $\mathrm{C}_{20} \mathrm{H}_{36} \mathrm{O}_{2}$ & Linoleic acid ethyl ester \\
\hline 40 & 62.97 & 8.59 & 390 & $\mathrm{C}_{24} \mathrm{H}_{38} \mathrm{O}_{4}$ & Bis(2-ethylhexyl) phthalate \\
\hline
\end{tabular}

'Anticancer; ${ }^{2}$ Antioxidant (Data obtained from Dr. Duke's Phytochemical and Ethnobotanical databases) 
Table 5. Chemical compositions of the ethyl acetate extract (VII) of the filtrate of static culture broth of Streptomyces sp. D-EGY.

\begin{tabular}{|c|c|c|c|c|c|}
\hline No. & RT & Area \% & M.W & M.F. & Compound name \\
\hline 1 & 5.02 & 1.67 & 158 & $\mathrm{C}_{6} \mathrm{H}_{10} \mathrm{~F}_{4}$ & Hexane, 3,3,4,4-tetrafluoro \\
\hline 2 & 5.18 & 7.85 & 2904 & NA & unknown \\
\hline 3 & 5.98 & 0.29 & 72 & $\mathrm{C}_{4} \mathrm{H}_{8} \mathrm{O}$ & Butanal \\
\hline 4 & 6.07 & 0.44 & 383 & $\mathrm{C}_{18} \mathrm{H}_{37} \mathrm{NO}_{2} \mathrm{Si}_{3}$ & $\begin{array}{l}\text { 1-(4'-trimethysilyl oxy phenyl)-1-trimethylsilylox y-2- } \\
\text { methyltrime thylsilyl-amino ethane }\end{array}$ \\
\hline 5 & 7.80 & 18.37 & 240 & $\mathrm{C}_{16} \mathrm{H}_{16} \mathrm{O}_{2}$ & 3-(4Vinylbenzyloxy) benzyl alcohol \\
\hline 6 & 7.86 & 19.08 & 148 & $\mathrm{C}_{9} \mathrm{H}_{12} \mathrm{~N}_{2}$ & 1,2-Dimethyl-2-pyrrolino[3,2-c]pyridine' \\
\hline 7 & 9.98 & 0.39 & 192 & $\mathrm{C}_{11} \mathrm{H}_{12} \mathrm{O}_{3}$ & 3-Isopropoxyphthalid \\
\hline 8 & 11.25 & 0.51 & 2084 & NA & unknown \\
\hline 9 & 13.36 & 0.90 & 282 & $\mathrm{C}_{19} \mathrm{H}_{38} \mathrm{O}$ & 2-Nonadecanone \\
\hline 10 & 14.07 & 2.32 & 385 & $\mathrm{C}_{22} \mathrm{H}_{27} \mathrm{NO}_{5}$ & cis- $1,2,7,9,10$-pentamethoxy aporphine \\
\hline 11 & 15.02 & 0.63 & 990 & $\mathrm{C}_{60} \mathrm{H}_{78} \mathrm{~S}_{6}$ & $\begin{array}{c}\text { 1,4-Bis(3,3",4,4"-tetra butyl-2,2':5',2"-terthien-2-yl)-1,3- } \\
\text { butadiyne }\end{array}$ \\
\hline 12 & 20.52 & 0.57 & 122 & $\mathrm{C}_{7} \mathrm{H}_{6} \mathrm{O}_{2}$ & Benzoic acid \\
\hline 13 & 22.11 & 1.83 & 114 & $\mathrm{C}_{6} \mathrm{H}_{14} \mathrm{~N}_{2}$ & N,N'-Dimethyl piperazine \\
\hline 14 & 22.84 & 0.80 & 340 & $\mathrm{C}_{20} \mathrm{H}_{24} \mathrm{~N}_{2} \mathrm{O}_{3}$ & $\begin{array}{c}\text { (+-)-5-Oxo-2a,7-.alph a,19,20-tetrahydro-16 } \\
\text { epipleiocarpamine }\end{array}$ \\
\hline 15 & 23.13 & 0.83 & 257 & $\mathrm{C}_{14} \mathrm{H}_{27} \mathrm{NO}_{3}$ & 12-Dimethylamino-10oxododecanoic acid \\
\hline 16 & 23.86 & 0.51 & 339 & $\mathrm{C}_{15} \mathrm{H}_{21} \mathrm{~N}_{3} \mathrm{O}_{4} \mathrm{~S}$ & $\begin{array}{c}\text { Ethyl 2-[3'-(3"-methyl-1"-hydroxycarbonylbutyl) } \\
\text { thioureido)pyridine-3-carboxylate }\end{array}$ \\
\hline 17 & 24.24 & 3.42 & 216 & $\mathrm{C}_{12} \mathrm{H}_{24} \mathrm{O}_{3}$ & $\begin{array}{c}\text { Propanoic acid, 2-methyl-, 2-ethyl-3-hydroxyhexyl } \\
\text { ester }\end{array}$ \\
\hline 18 & 26.48 & 12.66 & 158 & $\mathrm{C}_{10} \mathrm{H}_{22} \mathrm{O}$ & 3-Octanol-3,6-dimethyl \\
\hline 19 & 39.05 & 0.67 & 242 & $\mathrm{C}_{15} \mathrm{H}_{30} \mathrm{O}_{2}$ & Pentadecanoic acid \\
\hline 20 & 40.54 & 0.60 & 256 & $\mathrm{C}_{16} \mathrm{H}_{32} \mathrm{O}_{2}$ & Tetradecanoic acid-12-methyl, methyl ester \\
\hline 21 & 43.70 & 0.74 & 270 & $\mathrm{C}_{17} \mathrm{H}_{32} \mathrm{O}_{2}$ & Pentadecanoic acid, 14-methyl-, methyl ester \\
\hline 22 & 43.78 & 0.36 & 242 & $\mathrm{C}_{13} \mathrm{H}_{26} \mathrm{O}_{2} \mathrm{Si}$ & $\begin{array}{c}\text { (S)-5,5-Dimethyl-4-((tert-butyldimethy|silyl)oxy)-2- } \\
\text { cyclopentenol 1, 2 }\end{array}$ \\
\hline 23 & 44.13 & 2.42 & 242 & $\mathrm{C}_{13} \mathrm{H}_{26} \mathrm{O}_{2} \mathrm{Si}$ & $\begin{array}{c}\text { (S)-5,5-Dimethyl-4-((tert-butyldimethylsilyl)oxy)-2- } \\
\text { cyclopentenol } 1,2\end{array}$ \\
\hline 24 & 44.97 & 0.87 & 270 & $\mathrm{C}_{17} \mathrm{H}_{34} \mathrm{O}_{2}$ & Hexadecanoic acid, methyl ester \\
\hline 25 & 46.15 & 0.75 & 873 & $\mathrm{C}_{41} \mathrm{H}_{47} \mathrm{NO}_{20}$ & Wilfortrine \\
\hline 26 & 46.24 & 1.54 & 447 & $\mathrm{C}_{16} \mathrm{H}_{19} \mathrm{~N}_{2} \mathrm{O}_{9} \mathrm{~S}_{2}$ & Glucobrassicin \\
\hline 27 & 46.73 & 1.05 & 378 & $\mathrm{C}_{27} \mathrm{H}_{54}$ & Cyclohexane-1,3,5-trimethyl 2octadecyl \\
\hline 28 & 47.16 & 0.34 & 284 & $\mathrm{C}_{18} \mathrm{H}_{36} \mathrm{O}_{2}$ & Octadecanoic acid \\
\hline 29 & 47.28 & 0.63 & 284 & $\mathrm{C}_{18} \mathrm{H}_{36} \mathrm{O}_{2}$ & Hexadecanoic acid-14methyl, methyl ester \\
\hline 30 & 47.54 & 2.00 & 210 & $\mathrm{C}_{11} \mathrm{H}_{18} \mathrm{~N}_{2} \mathrm{O}_{2}$ & $\begin{array}{l}\text { Pyrrolo[1,2-a]pyrazine -1,4-dione, hexahydro-3-(2- } \\
\text { methyl propyl) }\end{array}$ \\
\hline 31 & 47.80 & 1.59 & 256 & $\mathrm{C}_{16} \mathrm{H}_{32} \mathrm{O}_{2}$ & Hexadecanoic acid \\
\hline 32 & 48.01 & 0.32 & 170 & $\mathrm{C}_{6} \mathrm{H}_{10} \mathrm{~N}_{4} \mathrm{~S}$ & 2-Hydrazino-4-methyl6-methyl thiopyrimidine 1,2 \\
\hline 33 & 48.14 & 0.56 & 378 & $\mathrm{C}_{27} \mathrm{H}_{54}$ & Cyclohexane, 1,3,5-trimethyl-2-octadecyl \\
\hline 34 & 49.88 & 1.40 & 270 & $\mathrm{C}_{17} \mathrm{H}_{34} \mathrm{O}_{2}$ & Pentadecanoic acid, 14-methyl, methyl ester \\
\hline 35 & 50.24 & 0.32 & 294 & $\mathrm{C}_{19} \mathrm{H}_{34} \mathrm{O}_{2}$ & 9,12-Octadecadienoic acid, methyl ester \\
\hline 36 & 52.23 & 0.55 & 308 & $\mathrm{C}_{20} \mathrm{H}_{36} \mathrm{O}_{2}$ & Ethyl-9-cis-1 1-trans-octadecadienoate \\
\hline 37 & 52.42 & 1.01 & 310 & $\mathrm{C}_{20} \mathrm{H}_{38} \mathrm{O}_{2}$ & 9-Octadecenoic acid (Z)--, ethyl ester \\
\hline 38 & 53.04 & 0.34 & 586 & $\mathrm{C}_{36} \mathrm{H}_{58} \mathrm{O}_{6}$ & $\begin{array}{l}\text { Hexadecanoic acid, } 1 a, 2,5,5 a, 6,9,10,10 a- \\
\text { octahydro-5,5a-dihydroxy -4-(hydroxyl methyl)-1, } \\
\text { 2,3,22-Triacetoxystictane' }\end{array}$ \\
\hline 39 & 62.94 & 7.38 & 390 & $\mathrm{C}_{24} \mathrm{H}_{38} \mathrm{O}_{4}$ & $\begin{array}{l}\text { 1,2-Benzene dicarboxylic acid, diisooctyl ester } \\
\text { (4S,5S-)4-(tert-Butyl dimethyl silyloxy methyl) }\end{array}$ \\
\hline 40 & 75.12 & 1.47 & 679 & $\mathrm{C}_{35} \mathrm{H}_{52} \mathrm{~F}_{3} \mathrm{NO}_{5} \mathrm{Si}_{2}$ & $\begin{array}{l}-5 \text {-[(1R,4S,2E)-4-tert-b utyldiphenylsilyloxy-1 }(2,2,2 \text { - } \\
\text { trifluoroaceylamino) pent-2-enyl]-2,2-di methyl-1,3- }\end{array}$ \\
\hline
\end{tabular}
dioxolane ${ }^{1,2, *}$

M.F.: Molecular formula; M.W.: Molecular weight; RT: Retention time. 'Anticancer; ${ }^{2}$ Antioxidant (Data obtained from Dr. Duke's Phytochemical and Ethnobotanical databases). "'Smart drugs' enhance the processes associated with cognitive brain activity, allowing the user to experience positive benefits 
against R. tolonifera, A. flavus, F. oxysporum and Alternaria. Moreover, several Streptomyces was reported to produce antifungal secondary compounds and the antagonistic activity of Streptomyces and the fungal pathogens is related to these compounds such as chitinase, $\beta-1,3-$ glucanase, chitosanase, and protease which was documented to have have the ability to lyse fungal cell walls and suppress fungal growth and both exponential and stationary culture filtrates of Streptomyces sp exhibited antifungal activity (Wang et al., 2011).

In DPPH scavenging assay, the antioxidants reduced the purple coloured DPPH radical to a yellow coloured compound diphenylpicrylhydrazine and the extent of reaction depended on the hydrogen donating ability of the antioxidants. Although the scavenging abilities of the crude extract reported herein was lesser, it was evident that the extracts showed hydrogen donating ability and therefore could serve as free radical scavengers and acting possibly as primary antioxidants. According to Taylor et al. (2007), there is no satisfactory drug to control cancer which is known to be the leading cause of death in the world. The limited availability to control cancer drug resistance along with the emergence of new pathogens has led the expansion of the search for novel drug candidates. According to the criteria of the National Cancer Institute ( $\mathrm{NCl}$, USA), the crude extract is considered promising as an antitumor at $\mathrm{IC}_{50}$ of $\leq 30 \mu \mathrm{g} / \mathrm{mL}$ however; for a pure substance $I_{50}$ should be $\leq 4 \mu \mathrm{g} / \mathrm{mL}$, which corresponds to strong cytotoxic activity (Dalal et al., 2016). The $I_{50}$ values of the crude extract of actinomycetes secondary metabolites in this study were found to be lower $(18.4,9.97,0.85,5.5,4.21$, and $4.91 \mu \mathrm{g} /$ $\mathrm{mL}$ for extracts I, III, V, VI, VII, and VIII, respectively) than that specified by the $\mathrm{NCl}$ for crude extracts, thus they are promising for further purification. Among the members of actinomycetes genus, Streptomyces sp. is a dynamic producer of functional, bio-effective metabolites with broad pharmaceutical range having antimicrobial, antihelminthic, antitumor and antiviral agents (Ravikumar et al., 2008). The current study revealed that both the rotary shaker and static crude extract of the Streptomyces D-EGY showed the highest antimicrobial, antioxidant and anticancer properties. In this concern, Subashini \& Kannabiran (2014) indicated that secondary metabolites from actinomycetes, especially the genus Streptomyces, are considered one of the most important sources for novel anticancer agents. The results of the present study suggested that the potential cytotoxic activity of extract VII against HepG2 could be due to the bioactive compound 1, 2- benzene dicarboxylic acid and hexadecanoic acid which were identified as the main components of Streptomyces sp. D-EGY (Krishnan et al., 2014). The mechanism by which these bioactive compounds can induce their cytotoxicity was suggested by the interference with basic cellular functions such as cell cycle, apoptosis, inflammation, angiogenesis, invasion and metastasis (Abe et al., 1993). The GC-MS results also revealed that complex mixture of numerous compounds were discovered. These results were similar to those reported by Ashok et al. (2014) who analysed secondary metabolites of Streptomyces albus and identified 8 compounds included 1-Octanol 2,7dimethyl which exhibited anticancer properties. Moreover, Abd-Elnaby et al. (2016) analysed Streptomyces parvus crude extract by GC-MS and found among others benzoic acid.

\section{Conclusion}

Streptomyces isolated from soil and marine sediments samples present varying degrees of antagonism against different pathogenic microorganisms. The crude extract of the isolates 5S1, 5S2 and D present greater antimicrobial, antioxidant and anticancer activity. Among them, the D-EGY isolate is the most effective. The chemical composition of these extracts revealed that they contain 40 chemical compounds two of them are well known as anticancer.

\section{Acknowledgment}

This work was funded by the National Research Centre, Cairo, Egypt, under grant \# 10070208.

\section{References}

Abdalhai, M.H., Fernandes, A.M., Xia, X., Musa, A., Ji, J., Sun, X. 2015. Electrochemical Genosensor 
To Detect Pathogenic Bacteria (Escherichia coli 0157:H7) As Applied in Real Food Samples (Fresh Beef) To Improve Food Safety and Quality Control. Journal of Agriculture and Food Chemistry 63(20):5017-5025.

Abd-Elnaby, H., Abo-Elala, G., Abdel-Raouf, U., Abdelwahab, A., Hamed, M. 2016. Antibacterial and anticancer activity of marine Streptomyces parvus: optimization and application. Biotechnology and Biotechnological Equipment 30(1):180-191.

Abe, N., Nakakita, Y., Nakamura, T., Enoki, N., Uchida, H., Munekata, M. 1993. Novel antitumor antibiotics, saptomycins. I. Taxonomy of the producing organism, fermentation, HPLC analysis and biological activities. Journal of Antibiotic (Tokyo) 46:1530-1535.

Ashok, G., Karthikeyan, P., Panneerselvam, A., Senthilkumar G. 2014. Effect of antimicrobial activity of UV mutated actinomycetes SP isolated from mangroves. European Journal of Experimental Biology4(5):46-52.

Cheong, E.Y.L., Sandhu, A., Jayabalan, J., Le, T.T.K., Nhiep, N.T., Ho, H.T.M., Zwielehner, J., Bansal, N., Turner, M.S. 2014. Isolation of lactic acid bacteria with antifungal activity against the common cheese spoilage mould Penicillium commune and their potential as biopreservatives in cheese. Food Control 46:91-97.

Dalal, K., Munuganti, R., Morin, H., Lallous, N., Rennie, P.S., Cherkasov, A. 2016. Drug-Discovery Pipeline for Novel Inhibitors of the Androgen Receptor. Methods in Molecular Biology 1443:3154.

Janardhan, A., Kumar, A.P., Viswanath, B., Saigopal, D.V.R., Narasimha, G. 2014. Production of bioactive compounds by actinomycetes and their antioxidant properties. Biotechnology Research International 2014:1-8.

Kekuda, T.R.P., Shobha, K.S., Onkarappa, R. 2010. Fascinating diversity and potent biological activities of actinomycetes metabolites. Journal of Pharmacy Research 3:250-256.

Khamna, S., Yokota, A., Peberdy, J.F., Lumyong, S. 2009. Antifungal activity of Streptomyces spp. isolated from rhizosphere of Thai medicinal plants. International Journal of Integrative Biology 6(3):143-147.

Krishnan, K., Mani, A., Jasmine, S. 2014. Cytotoxic activity of bioactive compound 1, 2- Benzene Dicarboxylic Acid, Mono 2- Ethyl hexyl Ester extracted from a marine derived Streptomyces sp. VITSJK8. International Journal of Molecular and Cellular Medicine 3(4):246-254.

Lim, S.W., Kim, J.D., Kim, B.S., Hwang, B. 2000.
Isolation and numerical identification of Streptomyces humidus strain S5-55 antagonistic to plant pathogenic Fungi. Plant Pathology Journal 16(4):189-199.

Myer, P.R., Kim, M., Freetly, H.C., Smith, T.P. 2016. Evaluation of 16 S rRNA amplicon sequencing using two next-generation sequencing technologies for phylogenetic analysis of the rumen bacterial community in steers. Journal of Microbiological Methods 127:132-140.

Patel, J.D., Parmar, M., Patel, P., Rohit, P., Taviyad, R., Ansari, P., Singh, P.K. 2014. Dynamism of antimicrobial activity of actinomycetes a case study from undisturbed microbial niche. Advances in Microbiology 4: 324-334.

Ravikumar, Y.S., Mahadevan, K.M., Kumaraswamy, M.N., Vaidya, V.P., Manjunatha, H., Kumar, V., Satyanarayana, N.D. 2008. Antioxidant, cytotoxic and genotoxic evaluation of alcoholic extract of Polyalthia cerasoides (Roxb.) Bedd. Environmental Toxicology and Pharmacology 26(2):142-146.

Shaaban, M., Abdel-Razik, A.S., Abdel-Aziz, M.S., AbouZied, A.A., Fadel, M. 2013. Bioactive secondary metabolites from marine Streptomyces albogriseolus isolated from red sea coast. Journal of Applied Sciences Research 9(1):996-1003.

Sineva, O.N., Terekhova, L.P. 2015. Selective isolation of rare actinomycetes from soil. Antibiot Khimioter 60(7-8):27-33.

Subashini, E, Kannabiran K. 2014. Isolation and identification of anti-ESBL (extended spectrum $\beta$-lactamase) compound from marine Streptomyces sp. VITSJK8. Journal Advances in Science Research 5:13-18.

Subathra, D.C., Amrita, K., Nitin, J., Jemimah, N.S., Mohana, S.V. 2013. Screening of actinomycetes isolated from soil samples for antibacterial and antioxidant activity. International Journal of Pharmacy and Pharmaceutical Science 5(4):483489.

Subramani, R., Aalbersberg W. 2012. Marine actinomycetes: An ongoing source of novel bioactive metabolites. Microbiological Research 167(10):571-580.

Sugita, T., Nishikawa, A. 2003. Fungal identification method based on DNA sequence analysis: Reassessment of the methods of the pharmaceutical society of Japan and Japanese pharmacopoela. Journal of Health Science 46(6):531-533.

Targowski T, Płusa T. 2015. Overall principles of treatment in case of toxicological threats. Polski Merkuriusz Lekarski 39(231):191-193. 
Taylor, M.W., Radax, R., Steger, D., Wagner, M. 2007. Sponge-associated microorganisms: evolution, ecology, and biotechnological potential. Microbiology and Molecular Biology Reviews 71:295-347.

Thirumalairaj, J., Shanmugasundaram, T. Sivasankari, K., Natarajaseenivasan, K. Balagurunathan, R. 2015. Isolation, screening and characterization of potent marine Streptomyces sp. PM105 against antibiotic resistant pathogens. Asian Journal of Pharmaceutical and Clinical Research 8(2):439-443.

Waller, R.A., Duncan, D.B., 1969. A Bayes rule for the symmetric multiple comparisons problem. Journal of the American Statistical Association 64 (328): 1484-1503

Wang, S.L., Liang, T.W., Yen, Y.H. 2011. Bioconversion of chitin-containing wastes for the production of enzymes and bioactive materials. Carbohydrate Polymers 84(2):732-742. 